\title{
Implementation of the Competence-Based Learning in Rwandan Physics Classrooms: First Assessment Based on the Reformed Teaching Observation Protocol
}

\author{
Kizito Ndihokubwayo ${ }^{1 *}$, Jean Uwamahoro ${ }^{1}$, Irénée Ndayambaje ${ }^{2}$ \\ ${ }^{1}$ African Center of Excellence for Innovative Teaching and Learning Mathematics and Science (ACEITLMS), University of Rwanda \\ College of Education (URCE), RWANDA \\ ${ }^{2}$ Rwanda Education Board (REB), RWANDA
}

Received 14 April 2020 - Accepted 15 June 2020

\begin{abstract}
Regular class observations are one of the means to monitor factors and dynamics that influence quality learning. From 2016, the Rwanda education system introduced a new curriculum known as Competence-Based Curriculum ( $C B C)$, which ensures fosters more the learner-centered approach. This study was carried out to assess CBC input after four years of implementation. For this assessment, the reformed teaching observation protocol (RTOP) was used to observe 42 classes from 17 classrooms taught by nine teachers from the eastern province and Kigali city in Rwanda. Outcomes of our analysis indicated that after four years of CBC implementation, learners' active participation has improved. The overall aggregate scores of observed lessons were 2.16 out of 4 ratings (54\%) across all the 25 RTOP statements. Grouping the RTOP statements into six factors, learner-centered physics class is practiced at a $61 \%$ level while the overall reformed physics class is at a level of $53 \%$. The results of this study led us to formulate some recommendations that would more improve physics students' active learning.
\end{abstract}

Keywords: teacher-centered class, learner-centered class, RTOP, CBC, Rwandan physics classroom

\section{INTRODUCTION}

Four years ago, a new curriculum, known as Competence-Based Curriculum (CBC), was introduced in Rwanda (REB, 2015b). The CBC intends to provide learners not only with knowledge but also skills to apply the new knowledge and be able to solve problems of the daily life experience practically. In $C B C$, learners should be actively engaged in learning activities and, therefore, the need to shift from teacher-centered to learnercentered learning approaches.

Before the implementation of CBC, Rwanda's education used the knowledge-based curriculum. The last favored the teacher-centered approach, where teachers are interested in completing the syllabus and serve as masters of learning. A study conducted in 2014 and reported in 2019 by Nzeyimana and Ndihokubwayo revealed that the teacher was in the center of knowledge while the learner was a listener during science and elementary technology class. Currently, Ukobizaba et al.
(2019) showed how Rwandan students appreciate caring teachers who motivate them to enjoy learning. However, teachers still need to foster learner-centered methods to boost problem-solving skills, innovation, and creativity among learners. Despite the training Rwanda Education Board (REB) and developmental partners (DPs) have so far provided to teachers (Ndihokubwayo \& Murasira, 2019; Ndihokubwayo et al., 2019), teaching improvement is not yet realized. The group work is mostly used by teachers thinking it can serve as an effective method and learner-centered approach (Byusa et al., 2020). However, the study showed that it was not the case because teachers practice teacher-centered related strategies such as lecturing and writing on the blackboard.

Teacher centered is a teaching method where the teacher takes most of the time explaining to and demonstrating for the passive students. Teachers prefer this method due to the time limit during listening to the learners (O'Sullivan, 2004; Qhobela \& Moru, 2014),

(c) $\mathbf{2 0 2 0}$ by the authors; licensee Modestum. This article is an open access article distributed under the terms and conditions of the Creative Commons Attribution License (http://creativecommons.org/licenses/by/4.0/). 


\section{Contribution to the literature}

- The study analyzed and presented the status of learners participation in Rwanda secondary school physics classrooms.

- The study assesses the changes or progress made in physics classrooms after four years of implementation of the new curriculum.

- The study outcomes inform teachers and education policymakers on the benefits of a new curriculum being implemented and areas to be improved.

learners' characters (Qhobela \& Moru, 2014), and insufficient resources (O'Sullivan, 2004). Despite teacher-centered, the learner-centered class should engage students, allowing them to manipulate hands-on tools, participate in discoveries, and collaborate with their classmates. In this regard, the teacher should stay as an observer, guider, and collaborator, where he/she orients the students to the objective of the lesson.

One important goal of teaching physics in schools of general education is that it should help students to understand and cope with their everyday life. However, the low understanding of optics and misconceptions faced by Rwandan students was associated with the poor instructional strategies used by teachers (Ndihokubwayo et al., 2020). The CBC requires teaching practices to shift to learner-centered pedagogy (LCP) approaches. In this era of learner-centered enhancement, many research institutions are financing various studies to investigate relevant tools and strategies for the better of the learning improvement. To track the level of this learning improvement, several researchers have developed the tools. Among the tools, classroom protocols have shown an invaluable tracking device of teaching and learning practices.

Classroom observation from other tools such as score achievement, conceptual understanding, attitude, and student learning interest scales has served a great tool since it shows off by not only descriptive or inferential statistics but also by our naked eye. It is an excellent teaching and learning assessment tool that has been ever used in the literature and the classroom environment. There have been various observation protocols, and all of them have clearly shown the classroom atmosphere depending on each protocol objective. For instance, Flanders Interaction Analysis (Flanders, 1970); Observing patterns of adaptive learning (Patrick et al., 1997); Reformed Teaching Observation Protocol (Piburn et al., 2000); UTeach observation protocol (Walkington et al., 2012); Teaching dimensions observation protocol (Hora, 2013); and The Classroom Observation Protocol for Undergraduate STEM (Smith et al., 2013) all have been created for different purposes.

Specifically, reformed teaching observation protocol (RTOP) tells how aligned practices are with studentcentered pedagogical practice (Sawada et al., 2000). Reform means the shift from traditional instructional strategies to more active and constructivist teaching strategies. In a reformed class, the teacher talks less and allows students to dialogue, discuss, and collaborate. RTOP was constructed on three main components; standards-based, inquiry-oriented, and studentcenteredness (Sawada et al., 2002). Therefore, it shows a relationship between a reformed teaching and the significant magnitude of learning. Compared to other protocols, RTOP is an inductive tool as it is an easy tool to be confirmed by several observers with high interobserver reliability (Piburn et al., 2000). It was made as an easy to use, valid, reliable tool, and dedicated to science and mathematics subjects (Sawada et al., 2002).

The present study adopted the constructivism theory of John Dewey (1933 - 1998) considered as the philosophical founder of this approach. In this theory, Piaget (1970) stated that children study thoroughly through doing and dynamically discovering their surroundings. Therefore, Onwioduokit (2013) recommends that science should be taught while learners are busy with useful activities. Additionally, learners are encouraged to doing something as a means of learning instead of only just leaning something (Demirci, 2009; Yilmaz \& Ince, 2012). Precisely, the social constructivism of Vygotsky (1978) guides this study as learners need to build knowledge altogether and employ their skills collaboratively to achieve lesson objectives and attain the global goal. Social constructivists argue that teachers do not have to transfer knowledge from their heads to the learners because learners construct their understanding through negotiation within their social setting. This theory infers that during the teaching and learning process, a teacher should not be an instructor instead of a facilitator.

This study aims at exploring the Rwandan physics classroom to track the student-centered approach after implementing $\mathrm{CBC}$. We wanted to assess how far physics classroom or teaching physics is reformed, which was not the case in most of the available literature. The study is not only crucial to Rwandan teachers but also others in the rest of the world because it informs how to track students learning and recommends what teachers should do to more focal point their students. 


\section{METHODOLOGY AND PROCEDURES}

\section{Research Design}

This study is based on classroom observation. To carry out this study, we used the Reformed Teaching Observation Protocol (RTOP) developed by Piburn et al. (2000). This protocol helped us to explore and evaluate how learners were learning. In this case, while an overt participant observation (Fraenkel et al., 2012) was considered to let students aware that the process of observation is taking place, it also allowed us more interaction with students. We observed nine teachers teaching in 17 classrooms from Rwanda. Six schools where these nine teachers teach were randomly selected from those which accommodate Physics subjects. We sampled four schools from the eastern province and two from Kigali city. Classrooms observed were purposively sampled from grades 10 and 11 (secondary 4 and 5) targeting geometric and physical optics teaching load (REB, 2015a) during the first three months of the academic year 2019. However, due to the speed of teachers, we were obliged to observe other lessons apart from optics.

The research proposal to conduct this study was submitted and accepted by the University of Rwanda College of Education (URCE) Directorate of research and innovation. The ethical clearance was then obtained from respective districts that host schools in which we conducted this study. Before observing classes, we explained the purpose and the scope of our research to teachers and students, where all of them signed the consent forms for voluntary participation. Every time before coming to class, we informed the respective teacher at least a week before. We in total observed 42 classes (21 in grade 10 and 21 in grade 11) where $60 \%$ of the total classes were optics related lessons (thin lenses, simple and compound microscopes, and wave and particle nature of light). In contrast, $40 \%$ were observed in other units, such as moments and equilibrium of bodies, simple harmonic, and forced oscillations. Among observed classes, 15 (36\%) took place in rural schools, while 27 (64\%) took place in urban schools.

\section{Sample Characteristics}

All the observed teachers have a background of education added to their teaching content. For instance, seven out of nine teachers have all graduated at the former Kigali Institute of Education (current UR-CE) and have been awarded a bachelor of physics with education. Among these teachers, some teach only physics, while others teach physics with either chemistry or mathematics. Among two out of nine who graduated from other institutions, one got applied physics while another got a pure physics degree. However, they later studied for a postgraduate diploma in education (PGDE) offered by URCE qualifying them as teachers. All the teachers have a teaching experience above three years, and everyone has got a minimum of one CBC training. Thus, all these nine teachers qualify for teaching physics in secondary schools, and these characteristics validate our classroom observation practice.

\section{Reformed Teaching Observation Protocol (RTOP)}

In this study, we used the RTOP that was developed to checking teacher and learner centeredness (Sawada et al., 2000). It was designed, piloted, and validated by the Evaluation Facilitation Group (EFG) of the Arizona Collaborative for Excellence in the Preparation of Teachers (ACEPT). Daiyo Sawada externally evaluated it, and Michael Piburn assessed it internally. The EFG was composed by Kathleen Falconer, Jeff Turley, Russell Benford, and Irene Bloom. The protocol consists of two parts - the background and grading parts.

The background information includes the location, teacher's name, experience, and certification, subject observed, grade level, observer name, date of observation, start and end time of observation, and the lesson title. Therefore, the observer needs to report if the teacher was informed or not to avoid distortion of findings.

The grading part consists of 3 themes - lesson design and implementation, content, and classroom culture. These themes split into five sub-themes, and each subtheme comprises five statements where every statement is ranked on five scales from 0 as never occurred to 4 as very descriptive or frequently observed. These subthemes are (a) lesson design and implementation, (b) propositional knowledge, (c) procedural knowledge, (d) communicative interaction, and (e) student/teacher relationship. The scales provide the degree to which statement was characteristic of the lesson observed but not the number of occurrences. Possible scores range from 0 to 100 points, with higher scores reflecting a greater degree of reform (Piburn et al., 2000; Sawada et al., 2000).

\section{Data Analysis}

In the study plan phase, we (a team of three observers) read the RTOP training manual (Piburn et al., 2000) and observed several videos of physics class for reliability calculation. Krippendorff (2011) defines reliability as a prerequisite to validity, the extent to which different methods, research results, or people arrive at the same interpretations or facts (p. 94). Interobserver reliability is a measure of consistency between two or more observers of the same construct. We computed the rate agreement (rate of agreement = number of agreements between 2 observers / total number of possible agreements) after watching the first video, and we found the $.69, .66$, and .54 inter-observer reliability coefficients among the three pairs. We watched a second video, and the agreement rate was still 
Table 1. Rwandan Physics classroom. The 25 RTOP Statements are from five themes: (a) lesson design and implementation (1-5), (b) propositional knowledge (6-10), (c) procedural knowledge (11-15), (d) communicative interaction (16-20), and (e) student/teacher relationship (21-25).

\begin{tabular}{|c|c|c|}
\hline RTOP Statements & Scores & Mean \\
\hline The instructional strategies and activities respected students' prior knowledge and the preconceptions inherent therein & 101 & 2.40 \\
\hline The lesson was designed to engage students as members of a learning community & 105 & 2.50 \\
\hline In this lesson, student exploration preceded the formal presentation & 82 & 1.95 \\
\hline This lesson encouraged students to seek and value alternative modes of investigation or problem-solving & 102 & 2.43 \\
\hline The focus and direction of the lesson was often determined by ideas originating with students & 71 & 1.69 \\
\hline The lesson involved fundamental concepts of the subject & 118 & 2.81 \\
\hline The lesson promoted strongly coherent conceptual understanding & 81 & 1.93 \\
\hline The teacher had a solid grasp of the subject matter content inherent in the lesson & 119 & 2.83 \\
\hline Elements of abstraction (i.e., symbolic representations, theory-building) were encouraged when it was important to do so & 91 & 2.17 \\
\hline Connections with other content disciplines and/or real-world phenomena were explored and valued & 67 & 1.60 \\
\hline $\begin{array}{l}\text { Students used a variety of means (models, drawings, graphs, concrete materials, manipulative, etc.) to represent } \\
\text { phenomena }\end{array}$ & 82 & 1.95 \\
\hline Students made predictions, estimations and/or hypotheses and devised means for testing them & 65 & 1.55 \\
\hline Students were actively engaged in a thought-provoking activity that often involved the critical assessment of procedures & 88 & 2.10 \\
\hline Students were reflective about their learning & 89 & 2.12 \\
\hline Intellectual rigor, constructive criticism, and the challenging of ideas were valued & 76 & 1.81 \\
\hline Students were involved in the communication of their ideas to others using a variety of means and media & 67 & 1.60 \\
\hline The teacher's questions triggered divergent modes of thinking & 103 & 2.45 \\
\hline There was a high proportion of student talk, and a significant amount of it occurred between and among students & 80 & 1.90 \\
\hline Student questions and comments often determined the focus and direction of classroom discourse & 73 & 1.74 \\
\hline There was a climate of respect for what others had to say & 106 & 2.52 \\
\hline Active participation of students was encouraged and valued & 120 & 2.86 \\
\hline Students were encouraged to generate conjectures, alternative solution strategies, and ways of interpreting evidence & 83 & 1.98 \\
\hline In general, the teacher was patient with students & 102 & 2.43 \\
\hline The teacher acted as a resource person, working to support and enhance student investigations & 112 & 2.67 \\
\hline The metaphor "teacher as a listener" was very characteristic of this classroom & 88 & 2.10 \\
\hline Overall scores & 2271 & 2.16 \\
\hline
\end{tabular}

low (below .7). We revised RTOP statements and discussed what everyone rated in the previous first and second videos. We then watched the third video. After watching the third video, we performed reliability among pairs of observers, and the coefficients were .90, .88 , and .95, which are considered high-reliability coefficients.

In the activity of classroom observation using rating scales, a specific reliability estimate should be applied. For instance, the researchers need to make attention to analyzing such data as some of the observer agreements may be due to chance. Therefore, to remove the agreement due to chance, we computed Cohen's Kappa coefficient of inter-observer agreement using SPSS. Cohen's Kappa $=(\mathrm{AO}-\mathrm{AC}) /(1-\mathrm{AC})$ where OA is the rate of agreement between observers, and $\mathrm{AC}$ is the rate of the inter-observer agreement occurred due to chance. $\mathrm{AC}$ is the sum of disagreement products between observers (what was observed by observer-1 only, and what was observed by observer-2 only). We found the coefficient .76, .85, and .91 of Kappa across three observer pairs. Cohen's Kappa coefficient (Cohen, 1988) ranges from 0 (insignificant agreement due to chance) up to the maximum value of perfect agreement between observers (1). Values below 0.4 indicate poor agreement; 0.7 is the minimum acceptable level while higher than 0.75 indicates excellent agreement.

While watching, we also recorded the classroom activities in the form of notes. Then, after class, each observer filled the rest of the protocol using his/her notes he/she wrote and what he/she remembered was done in the classroom. In analyzing RTOP data, we used Ms. Excel, where we recorded all the data by gathering all the observed classes. We vertically calculated the mean scores under each scale and horizontally along with each statement. We averaged the rate to figure out the learner centeredness in all observed classes as well as specifically in classes where hands-on activities dominate and where do not.

\section{DATA PRESENTATION AND RESULTS DISCUSSION}

By summing up all scores got from a range of 0 to 4 scales along with a total of 42 observations, we got 168 total scores for each RTOP statement. Table 1 displays the order and description of RTOP statements, their scores, and their respective average scores (mean) calculated from scores of each statement overall 42 observations.

The overall average performance was 2.16 out of 4 scores $(54 \%)$ across all the 25 RTOP statements. The lowest score of 1.55 (39\%) was found at statement 12 (Students made predictions, estimations, and/or hypotheses and devised means for testing them). In comparison, the highest score of $2.86(71 \%)$ was obtained at statements 21 (active participation of students was encouraged and valued). Teachers encouraged students' 
participation because apart from the educational degree, all teachers in Rwanda have accumulated a bunch of pedagogical training through REB or educational DPs. These training foci on the implementation of $\mathrm{CBC}$ by reviewing lesson preparation and putting learners in the center of learning. Among the 42 observed classes, the lowest class got $21 \%$ scores, and the highest class got $88 \%$ scores. Similarly, during RTOP statement difficulties in the Amrein-beardsley and Popp (2012) study, statement 12 was the most challenging, while 23 was the least. In addition to statement 12, teachers also showed weaknesses in statements $3,5,7,10,11,15,16,18,19$, and 22

Most of the teachers started with a presentation instead of letting students explore the phenomenon first (statement 3). For instance, the teacher started teaching and explaining the telescope and brought the students out after. This act confuses students as they are not able to experience complex and abstract concepts from simple and concrete concepts and takes source from the teachers' time conception. For instance, in statement 24 and 25 , teachers were rushing and did not care much of ideas from students. It also shows why the same classes suffered from low scores at statement 5 , where teachers do not value the insights from students. Teachers should use the ideas originated from their learners in their formal presentation. This practice motivates students and assures teachers the degree they know and care about the students.

Teachers were observed not promoting coherent conceptual understanding (statement 7). This behavior shows why the subject matter cannot stand alone even if teachers try to use symbolic representation. Still, these representations are not enough as connecting physics content with other disciplines and/or real-world phenomena (statement 10) was low among observed classes. We observed such behavior in only two classes where one teacher demonstrated a differential equation of forced oscillations and another used vector function to explain the turning effect of the moment of a force. Most teachers used drawings (statement 11) on blackboard such as drawing the lens, working principle of the microscope, and swinging spring balance. However, some graphs and concrete materials were not handled appropriately. An example was where two teachers were experimenting on the refraction phenomenon (determination of Snell's refractive indices) using a plain white paper, a ruler, a glass block, four pins, and a soft board.

Another example was where one teacher brought students outside the class after studying the telescope. In both examples, teachers cared much about time than the outcome of the experiment. In the first example, learners were left without accurately plotting the gradient of the sine function graph while in the second experiment teacher requested students to observe trees and mountain using two empty lens glasses (without telescope tube). However, this would be difficult to see far objects reflecting the concept of a telescope as much light will rise between two lenses. It is why it is difficult for students to estimate and formulate hypotheses (statement 12) and, therefore, lose scientific reasoning due to wrong conjectures. Therefore, engaging students as entertainment is not enough if the aim of capturing the target concept is not achieved.

In our findings, teachers did not exhibit practices that encourage intellectual rigor, constructive criticism, and the challenging of ideas (statement 15). This behavior affects the communication of students using a variety of means and media (statement 16). Although one belongs to procedural knowledge and another to communicative interaction, they influence each other. It is evident that if the teacher does not give room to students for communicating their ideas, constructive criticism will also become low. The effort for a cure should take a source from effective questioning triggering different modes of thinking. A valid interpretation comes from effective questioning. However, if a teacher takes more time talking more than students do (statement 18), as a result, the students' comments cannot determine the focus of classroom discourse (statement 19) as in our case even though students respect their classmates' ideas. Nevertheless, expressing their ideas is a good starting point to remedy the teacher's talk rate and studentfocused discussion.

Although active participation was valued, however, teachers did not much encourage students to generate conjectures and provide alternative solution strategies (statement 22). Thus, it shows how teachers avoid being challenged by students in various ways of thinking. Teachers think that it is kind of wasting time. Nonetheless, this increases the students' collaboration hence enhancing interest and conceptual understanding. Teachers should be patient enough to let students express themselves and challenge each other as the social constructivism theory pinpoints it. In this case, the teacher should be in a position to guide the discussion and help students draw an appropriate conclusion.

RTOP is made up of three themes showing the role of classroom design, teaching content, and classroom management. The last two themes split into two subthemes adding on the first themes to make five subthemes (see Table 2). Table 1 only presents the individual score of each of 25 statements. Therefore, we cumulated 25 statements into five sub-themes to overall look at the reformed practice in a specific mode. Table 2 displays these sub-themes results as a summary of all 25 statements.

By averaging scores from each of five sub-themes, $2.20,2.27,1.90,2.04$, and 2.40 mean scores were obtained from the first to the fifth sub-theme, respectively. Note that these means together with the minimum, maximum, and standard deviations were calculated based on four 
Table 2. RTOP Sub-themes. Lesson design and implementation (statements 1-5), Content (propositional knowledge, statements 6-10 and procedural knowledge, statements 11-15), Classroom culture (communicative interaction, statements 6-10 and student/teacher relationship, statements 21-25)

\begin{tabular}{|c|c|c|c|c|c|c|}
\hline Themes & Sub-themes & $\mathrm{MIN}$ & MAX & MEAN & STD & $\%$ \\
\hline Lesson design and implementation & Lesson design and implementation & 1.69 & 2.50 & 2.20 & 0.36 & $55 \%$ \\
\hline \multirow[t]{2}{*}{ Content } & Propositional knowledge & 1.60 & 2.83 & 2.27 & 0.55 & $57 \%$ \\
\hline & Procedural knowledge & 1.55 & 2.12 & 1.90 & 0.24 & $48 \%$ \\
\hline \multirow[t]{2}{*}{ Classroom culture } & Communicative interaction & 1.59 & 2.52 & 2.04 & 0.42 & $51 \%$ \\
\hline & Student/Teacher relationships & 1.97 & 2.86 & 2.40 & 0.37 & $60 \%$ \\
\hline
\end{tabular}

Table 3. Analysis of 6 groups. The MEAN score is computed on a $0-4$ scale. STD is the average standard deviation across all classified statements under each factor. The percentage is calculated based on the mean over the total range (4) scores

\begin{tabular}{llcccc}
\hline & Factors & RTOP Statements & MEAN & STD & $\%$ \\
\hline 1 & Pedagogy of inquiry teaching & $3,4,11,12,13,14,16$ & 1.96 & 1.56 & $49 \%$ \\
2 & Propositional knowledge & $6,7,10$ & 2.11 & 1.43 & $53 \%$ \\
3 & Content pedagogical knowledge & $1,5,15,22$ & 1.97 & 1.58 & $49 \%$ \\
4 & Community of learners & $2,18,20,21,24,25$ & 2.42 & 1.43 & $61 \%$ \\
5 & Reformed teaching & $9,17,19$ & 2.12 & 1.51 & $53 \%$ \\
6 & Teacher's patience & 8,23 & 2.63 & 1.36 & $66 \%$ \\
\hline
\end{tabular}

scores as total scores (4/4) from the range of 0 to 4 scale. In contrast, percentages were calculated based on the mean and full scores. The procedural knowledge needs more emphasis as our study and study of Amreinbeardsley and Popp (2012) both resulted in the lowest minimum, maximum, and mean score.

During validation of RTOP, Sawada et al. (2000) have performed the principal component analysis and got six factors more clarifying what is happening in the classroom. These factors are (a) pedagogy of inquiry teaching (consisting of 7 RTOP statements), (b) propositional knowledge (3 statements), (c) content pedagogical knowledge (4 statements), (d) the community of learners (6 statements), (e) reformed teaching (3 statements), and (f) teacher's patience (2 statements). We have analyzed our data and calculated the mean scores and percentages of these factors based on their classification (Table 3).

Table 3 clearly shows how the physics classroom in Rwanda looks. Teachers in observed classes scored 2.11 out of 4 scores (53\%) in propositional knowledge, 2.42 $(61 \%)$ in the community of learners, $2.12(53 \%)$ in reformed teaching, and $2.63(66 \%)$ in teacher's patience. Teachers scored above $50 \%$ in almost all the groups except in the pedagogy of inquiry teaching (49\%) and content pedagogical knowledge (49\%). Accurately, the community of learners reflects a learner-centered classroom, while reformed teaching reflects the overall classroom inquiry-based classroom. The reformed teaching score (53\% as in Table 3 ) is quite equal to the average total rating $(54 \%$ as in Table 1$)$ of all RTOP statements. Thus, it shows the reformed teaching of physics in Rwanda. However, teachers need to increase all areas of reformed education, specifically, pedagogy of inquiry teaching and content pedagogical knowledge.

\section{SUMMARY AND RECOMMENDATIONS}

Summed 25 statement scores ranged from 0-100; we got $54 \%$ RTOP scores. Grouping statements, $61 \%$, and $53 \%$ scores indicated the level of learner-centered and reformed teaching, respectively, among Rwandan physics classrooms. Note that "any RTOP score greater than 50 indicates a considerable presence of reformed teaching in a lesson (Macisaac \& Falconer, 2002, pp. 482)." Therefore, we found a considerable presence of reformed teaching of physics in Rwanda.

Although we concluded that Rwandan physics teachers implement $\mathrm{CBC}$ via learner-centered at a $61 \%$ level, however, we got some recommendations. Teachers should allow students to observe nature and manipulate the instruments via alternative modes of investigation before providing explanations to enhance their problem-solving ability. They need to trust their students and reserve time for learning reflection. Depending on the level of students, teachers should be able to guess what students want to mean even if their opinions are vague, therefore adjust and harmonize them for better understanding. Teachers need to connect what they teach in physics with real-life examples and other subjects such as geography, mathematics, chemistry, and biology to open the students' eyes for a comprehensive view of nature. Teachers should take seriously the lesson preparation such that teaching aids like models, drawings, graphs, symbols, concrete material are used appropriately and accurately.

RTOP is flexible to be used by teachers and lecturers to evaluate their teaching practices for the sake of improvement. After compromising on the meaning of all 25 statements, they should use RTOP by pair observation and perform after class discussion. Although the scores will not be accurate as ones for reliable and formal research, they with discussion will serve as your teaching reflection and insight (Macisaac \& Falconer, 2002) for direct or future reformed teaching. In the 
reformed class, the textbook-based approach is used less, and learners are busy in exploratory activities (Macisaac \& Falconer, 2002). Students should negotiate, reflect upon, and evaluate one another's opinions in groups, while teachers should be responsible for controlling the discussion, managing time, and rewarding students' discourse. In a large class where it is difficult for teachers or lecturers to guide and monitor the conversation, groups may exchange and negotiate amongst one another as well as within group (self-help).

Further researches should be directed to laboratorybased classes to investigate the level learners put what they learned into practices. Researchers should also replicate this study to other subjects to compare results and find a firm conclusion on CBC implementation.

\section{ACKNOWLEDGEMENT}

We appreciate the review comments provided by Professor Scott Franklin, Rochester Institute of Technology, NY, US. We would also like to pay thankful recognitions to RTOP authors -Daiyo Sawada and Michael Pibum - who developed it and put it open to use. Miss Juliette Itangishatse and Mr. Fidele Ukobizaba, their assistance in data collection, are also acknowledged.

The authors got full financial support from the African center of excellence for Innovative Teaching and Learning Mathematics and Science (ACEITLMS).

\section{REFERENCES}

Amrein-beardsley, A., \& Popp, S. E. O. (2012). Peer observations among faculty in a college of education: investigating the summative and formative uses of the Reformed Teaching Observation Protocol (RTOP). Educ Asse Eval Acc, 24, 5-24. https://doi.org/10.1007/s11092-0119135-1

Bloom, B. S., Engelhart, M. D., Furst, E. J., Hill, W. H., \& Krathwohl, D. R. (1956). Taxonomy of educational objetives: the classification of educational goals: handbook I: cognitive domain (No. 373.19 C734t). D. Mckay.

Byusa, E., Kampire, E., \& Mwesigye, A. R. (2020). Analysis of Teaching Techniques and Scheme of Work in Teaching Chemistry in Rwandan Secondary Schools. EURASIA Journal of Mathematics, Science and Technology Education, 16(6), 1-9. https:/ / doi.org/10.29333/ejmste/7833

Cohen, J. (1988). Statistical Power Analysis for the Behavioral Sciences (2nd Ed.). Lawrence Erlbaum Associates, Publishers.

Demirci, C. (2009). Constructivist Learning Approach in Science Teaching. HUJ Education, 37, 24-35. Retrieved from https:/ / dergipark.org.tr/en/pub/ hunefd/issue/7801/102225
Flanders, N. A. (1970). Analyzing Teaching Behavior. United States of America: Addison-Wesley Publishing Company.

Fraenkel, J. R., Wallen, N. E., \& Hyun, H. H. (2012). How to Design and Evaluate Research in Education (8th ed.). McGraw Hill.

Hora, M. T. (2013). Exploring the Use of the Teaching Dimensions Observation Protocol to Develop Fine grained Measures of Interactive Teaching in Undergraduate Science Classrooms. Retrieved from http:/ / www.wcer.wisc.edu/publications/workin gPapers/papers.php

Krippendorff, K. (2011). Communication Methods and Measures Agreement and Information in the Reliability of Coding. Communication Methods and Measures, 5(2), 93-112. https://doi.org/10.1080/ 19312458.2011.568376

Macisaac, D., \& Falconer, K. (2002). Reforming Physics Instruction Via RTOP. The Physics Teacher, 479(11), 479-485. https:/ / doi.org/10.1119/1.1526620

Ndihokubwayo, K., \& Murasira, G. (2019). Teachers' training college learners' expectations for their future teaching. LWATI: A Journal of Contemporary Research, 16(2), 1-10. Retrieved from https:/ / www. ajol.info/index.php/lwati/article/view/185978

Ndihokubwayo, K., Mugabo, R. L., \& Byusa, E. (2019). Training Strategies used in Strenghening Competence-Based Curriculum in Rwanda. Svietmas: Politika, Vadyba, Kokybe Education Policy, Management and Quality, 11(2), 77-87. Retrieved from http://oaji.net/articles/2019/513-15760941 62.pdf

Ndihokubwayo, K., Uwamahoro, J., Ndayambaje, I., \& Ralph, M. (2020). Light phenomena conceptual assessment: an inventory tool for teachers. Physics Education, 55(3), 035009. https://doi.org/10.1088/ 1361-6552/ab6f20

Nzeyimana, J. C., \& Ndihokubwayo, K. (2019). Teachers' Role and Learners' Responsibility in Teaching and Learning Science and Elementary Technology in Rwanda. African Journal of Educational Studies in Mathematics and Sciences, 15(2), 1-16. Retrieved from https://www.ajol.info/index.php/ajesms/article / view/188762

O'Sullivan, M. (2004). The reconceptualisation of learner-centred approaches: a Namibian case study. International Journal of Educational Development, 24, 585-602. https:/ / doi.org/10.1016/S0738-0593(03) 00018-X

Onwioduokit, F. A. (2013). The ordeal of science teaching in the contemporary society: A need for paradigm shift for the new generation. A Professorial Inaugural Lecture (Series 36th) Delivered on January 31st, 2013. University of Uyo, Nigeria. 
Patrick, H., Ryan, A. M., Anderman, L. H., Middleton, M. Linnenbrink, L., Hruda, L. Z., \& Midgley, C. (1997). OPAL. Observing patterns of adaptive learning: A protocol for classroom observations. Ann Arbor: University of Michigan.

Piaget, J. (1970). Science of Education and the Psychology of the Child. New York: Orion Press.

Piburn, M., Sawada, D., Turley, J., Falconer, K., Benford, R., Bloom, I., \& Judson, E. (2000). Reformed teaching observation protocol (RTOP) Training Guide. Tempe, Arizona: Arizona Collaborative for Excellence in the Preparation of Teachers. https://doi.org/ ED419696

Qhobela, M., \& Moru, E. K. (2014). Understanding Challenges Physics Teachers Come Across as they Implement Learner-centred Approaches in Lesotho. African Journal of Research in Mathematics, Science and Technology Education, 18(1), 63-74. https:/ / doi.org/10.1080/10288457.2014.884351

REB. (2015a). Advanced level Physics syllabus. Ministry of Education.

REB. (2015b). Competency Based Curriculum-Summary of Curriculum Framework Pre-Primary to Upper Secondary. Ministry of Education. Retrieved from http://reb.rw/fileadmin/competence_based_curr iculum/syllabi/curriculum_framework_final_prin ted.compressed.pdf

Sawada, D., Piburn, M., Falconer, K., Turley, J., Benford, R., \& Bloom, I. (2000). Reformed teaching observation protocol (RTOP). ACEPT Technical Report No. IN00-1). Tempe, AZ: Arizona Collaborative for Excellence in the Preparation of Teachers. Retrieved from http://www.public.asu.edu/ an ton1/Assess Articles/Assessments/Chemistry \% 20 Assessments/RTOP\%20Reference\%20Manual.pdf

Sawada, Daiyo, Piburn, M. D., Judson, E., Turley, J., Falconer, K., Benford, R., \& Bloom, I. (2002). Measuring Reform Practices in Science and
Mathematics Classrooms: The Reformed Teaching Observation Protocol. School Science and Mathematics, 102(6), 245-253. https://doi.org/ 10.1111/j.1949-8594.2002.tb17883.x

Smith, M. K., Jones, F. H. M., Gilbert, S. L., \& Wieman, C. E. (2013). The Classroom Observation Protocol for Undergraduate STEM (COPUS): A New Instrument to Characterize University STEM Classroom Practices. CBE - Life Sciences Education, 12, 618-627. https://doi.org/10.1187/cbe.13-080154

Ukobizaba, F., Ndihokubwayo, K., Mukuka, A., \& Uwamahoro, J. (2019). Insights of teachers and students on mathematics teaching and learning in selected Rwandan secondary schools. African Journal of Educational Studies in Mathematics and Sciences, 15(2), 93-107. Retrieved from https:/ / www.ajol.info/index.php/ajesms/article /view/192088

Vygotsky, L. S. (1978). Socio-cultural theory. Mind in society.

Walkington, C., Arora, P., Ihorn, S., Gordon, J., Walker, M., Abraham, L., \& Marder, M. (2011). Development of the UTeach Observation Protocol: A classroom observation instrument to evaluate mathematics and science teachers from the UTeach preparation program. UTeach Natural Sciences, University of Texas at Austin. Retrieved from https: / / uteach.utexas.edu/sites/default/files/UT OP_Paper_Non_Anonymous_4_3_2011.pdf

Yilmaz, O., \& Ince, E. (2012). The Usage of Alternative Assessment Techniques in Determination of Misconceptions about Electromagnetic FieldMagnetism Contents and Effects of Video-Based Experiments on Stu dents' Achievement at Distance Learning Course. 55, 155-160. https://doi.org/ 10.1016/j.sbspro.2012.09.489

\section{http://www.ejmste.com}

